\title{
Modeling Solidification Microstructures of Steel Round Billets Obtained by Continuous Casting
}

\author{
Giovanni STRAFFELINI, ${ }^{1)}$ Luca LUTTEROTTI, ${ }^{1)}$ Matteo TONOLLI ${ }^{1)}$ and Massimo LESTANI') \\ 1) Department of Materials Engineering and Industrial Technology, University of Trento, via Mesiano 77, Trento, 38050 Italy. \\ 2) STG Group S.p.A., Gessate, Milano, Italy.
}

(Received on March 4, 2011; accepted on May 16, 2011)

\begin{abstract}
The knowledge of the position of the columnar to equaxial transition (CET) is of paramount importance to evaluate the internal quality of continuous casting (CC) products. One way to control the operational CC conditions with the objective of assuring a given quality level is to develop a numerical program able to calculate the local solidification rate $(R)$, the local thermal gradient $(G)$ and the local time of solidification $\left(\mathrm{t}_{\mathrm{f}}\right)$ and to relate these parameters to the CET by means of a predictive model. In the present investigation, the dendritic morphology and the CET transition of three round billets made of a low carbon steel $(0.14 \% \mathrm{C})$ and produced by $\mathrm{CC}$ are characterized, and a computer model is developed to evaluate the $\mathrm{R}$, $\mathrm{G}$ and $\mathrm{t}_{\mathrm{f}}$-parameters. Referencing the well-known CET transition model developed by Hunt, a simple prediction equation is thus obtained for the steel under study and it is used to propose guidelines for the optimization of the CC operational parameters.
\end{abstract}

KEY WORDS: continuous casting; columnar to equiaxial ratio; solidification; prediction model; steel round billet.

\section{Introduction}

The solidification of steel products by continuous casting (CC) is continuously increasing. A fundamental task of the $\mathrm{CC}$ method is the optimization of the processing parameters to minimize the formation of defects in the products. ${ }^{1)}$

The grain structure of CC products is typically characterized by the presence of small grains in the outer chill zone, elongated grains in the intermediate columnar zone and randomly oriented grains in the central equiaxed zone. The transition from the columnar growth to equiaxed growth (usually called CET) occurs when the columnar front is blocked by the growing equiaxed grains nucleated in the liquid ahead of the solidifying front. ${ }^{2}$ The occurrence of such a transition can be predicted by Hunt's model: ${ }^{3)}$

$$
G<0.6 \cdot N_{0}^{1 / 3} \cdot \Delta T_{c} \cdot\left(1-\frac{\Delta T_{n}^{3}}{\Delta T_{c}^{3}}\right) .
$$

where $\mathrm{G}$ is the thermal gradient at the solidifying front, $\mathrm{N}_{0}$ is the number density of nuclei of critical size, and $\Delta T_{n}$ and $\Delta \mathrm{T}_{\mathrm{c}}$ are the nucleation and constitutional undercooling, respectively, in the liquid in which the grains grow.

The position of the CET is an important parameter since it plays a role in the formation of the internal defects. In particular, a large columnar region favors the formation of centerline segregation, cracks and porosity. Several experimental investigations show a clear decrease in the centerline segregation as the equiaxed zone ratio (given by the ratio of the length of the equiaxed to the columnar regions, measured on a product section) increases. ${ }^{1,45)}$ In practice, the equiaxed zone ratio is increased by optimizing the casting parameters such as the casting speed, the superheating of liquid steel in the tundish, and the cooling conditions, or by adopting specific electromagnetic stirrers that break the dendrite tips and thus increase the local density of equiaxed grains.

In steels solidified by $\mathrm{CC}$, solidification occurs with a dendritic morphology in both the columnar and the equiaxed regions. Two parameters are commonly used to characterize such a morphology, i.e., the primary $\left(\lambda_{1}\right)$ and secondary $\left(\lambda_{2}\right)$ arm spacing. These parameters can be evaluated by the following relations based on theoretical solidification models: ${ }^{6,7)}$

$$
\begin{gathered}
\lambda_{1}=\frac{N}{R^{1 / 4} \cdot G^{1 / 2}} \\
\lambda_{2}=M \cdot t_{f}^{1 / 3} .
\end{gathered}
$$

where $\mathrm{R}$ is the growth velocity of the columnar solidifying front, $\mathrm{t}_{\mathrm{f}}$ is the solidification time, and $\mathrm{N}$ and $\mathrm{M}$ are materials constants. ${ }^{7)}$ The secondary arm spacing $\left(\lambda_{2}\right)$ is an important microstructural parameter with regard to internal defects. ${ }^{5)}$

To optimize the CC parameters with the aim of reducing the internal defects, it is therefore of paramount importance to develop of a heat transfer model able to predict the parameters $\mathrm{G}, \mathrm{R}$ and $\mathrm{t}_{\mathrm{f}}$ on the product cross section, i.e., at the solidifying front for the whole metallurgical length. In this way it is possible to predict the role of the operating parameters including the tundish superheating, the cooling conditions, and the billet or slab size.

This work investigated the solidification (without stir- 
Table 1. Casting parameters.

\begin{tabular}{c|c|c|c|c|c|}
\hline & $\begin{array}{c}\text { Cast speed, } \\
\mathrm{m} / \mathrm{min}\end{array}$ & $\begin{array}{c}\text { Water flow rate in } \\
\text { mould, } \mathrm{m}^{3} / \mathrm{h}\end{array}$ & $\begin{array}{c}\text { Mould thickness, } \\
\mathrm{mm}\end{array}$ & $\begin{array}{c}\text { Temperature increase } \\
\text { of cooling water } \\
\text { in mould, }{ }^{\circ} \mathrm{C}\end{array}$ & $\begin{array}{c}\text { Cooling water in } \\
\text { the secondary region, } \\
1 / \mathrm{kg} \text {-steel }\end{array}$ \\
\hline $210 \mathrm{~mm}$ round billet & 1.1 & 110 & 18 & 5.4 & 0.75 \\
\hline $250 \mathrm{~mm}$ round billet & 1 & 115 & 20 & 5.7 & 0.55 \\
\hline $280 \mathrm{~mm}$ round billet & 0.8 & 120 & 22 & 5.4 & 0.45 \\
\hline $410 \mathrm{~mm}$ round billet & 0.5 & 147 & 24 & 5.3 & 0.3 \\
\hline
\end{tabular}

ring) of CC round billets with different diameters. A computer program was developed to simulate the casting process, and in particular to evaluate the parameters $G, R$ and $t_{f}$ as a function of the distance from the product surface. A simplified approach is then proposed to estimate the position of the CET and thus to obtain guidelines for the optimization of the $\mathrm{CC}$ process.

\section{Materials and Experimental Method}

Four steel round billets with diameters of 210, 250, 280 and $410 \mathrm{~mm}$ were produced by $\mathrm{CC}$. Their nominal chemical composition was: $0.14 \% \mathrm{C}, 1 \% \mathrm{Mn}, \quad 0.3 \% \mathrm{Si}, \quad 0.02 \% \mathrm{P}$, $0.015 \% \mathrm{~S}, 0.1 \% \mathrm{Cr}$, and $0.25 \% \mathrm{Cu}$. Table 1 summarizes the $\mathrm{CC}$ operating conditions. The pouring temperature was $1556^{\circ} \mathrm{C}$ for each billet, corresponding to a superheat in the tundish of $40^{\circ} \mathrm{C}$.

The round billets with a diameters of 210, 250 and 280 $\mathrm{mm}$ were submitted to a metallographic investigation. Two sections for each product were investigated with the aim of revealing their dendritic microstructures. For this, the samples were etched with the following solution:8) $4 \mathrm{~g} \mathrm{FeCl}_{3}$, $0.3 \mathrm{~g} \mathrm{CuCl}_{2}, 0.4 \mathrm{ml} \mathrm{HCl}, 50 \mathrm{ml} \mathrm{H} \mathrm{H}_{2} \mathrm{O}$. The etching duration was in the range of 30 to $60 \mathrm{~s}$. Figure 1 shows an example of the dendritic morphology in the case of the round with a diameter of $280 \mathrm{~mm}$.

The dendrite arm spacings $\lambda_{1}$ and $\lambda_{2}$ were measured using an image analyzer interfaced with the optical microscope. At the surface of each sample, a magnification of $12.5 \times$ was used. At the center, a magnification of $10 \times$ was used. The variation of $\lambda_{1}$ and $\lambda_{2}$ as a function of the distance from the surface was then obtained. For each section, the measurements were taken in two positions, i.e., from the surface to the center in two random directions forming an angle of $180^{\circ}$. The reported profiles are therefore the mean values of four measurements.

The microstructural observations also yielded the position of the CET. Four measurements were also taken for this parameter, and the average values are reported.

\section{Heat Transfer Model}

In $\mathrm{CC}$ products solidification starts in the mould where flowing water removes heat through the mould wall. Solidification then continues in the secondary zone, where water sprays remove heat from the solidifying surface. The advancement of the solidifying front up to complete solidification was studied using the Fourier equation for heat conduction under non-steady conditions, with the assumption that heat is extracted in the transverse section along the radial $\mathrm{r}$ coordinate $(\mathrm{r}=0$ at the center of the round billet $):^{1,9)}$ (a)

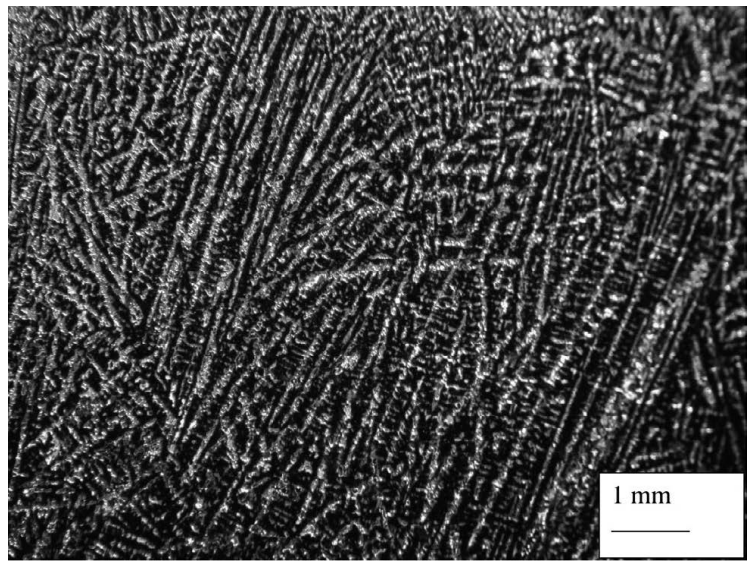

(b)

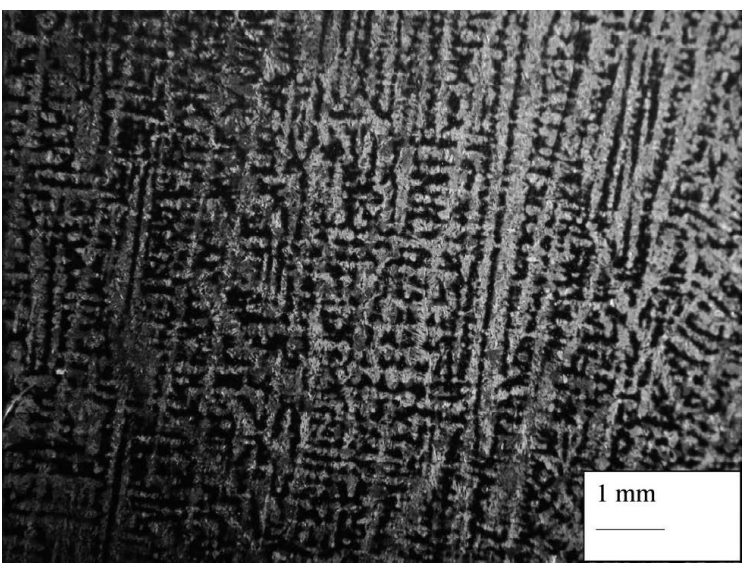

Fig. 1. Example of the dendritic morphology observed close to the surface (a) and at center (b) of the round billet with a diameter of $280 \mathrm{~mm}$.

$$
\frac{\delta}{\delta r}\left(k \cdot \frac{\delta T}{\delta r}\right)=\rho \cdot C_{p}^{*} \cdot \frac{\delta T}{\delta t}
$$

where $\mathrm{T}$ is the temperature, $\mathrm{t}$ is time, $\mathrm{k}$ is the thermal conductivity of the steel and $\mathrm{C}_{\mathrm{p}}{ }^{*}$, is its effective specific heat. For solid steel, k depends on temperature, and the relationship reported in Ref. 9 is used. For liquid steel, an effective value was selected to account for the effects of bulk convection. $\mathrm{k}$ was set to $100 \mathrm{~W} / \mathrm{mK}$, in agreement with data reported in Refs 10 and 11. In the mushy zone, $\mathrm{k}$ was calculated using the rule of mixtures. The fraction of solid in the mushy zone, $f_{s}$, depends on temperature and on the liquidus and solidus temperatures that were calculated using the relations reported in Ref. 12. The effective specific heat, $\mathrm{C}_{\mathrm{p}}{ }^{*}$, is defined as:

$$
C_{p}^{*}=C_{p}-L \cdot \frac{d f_{s}}{d T}
$$

where $C_{p}$ is the specific heat capacity of steel (for liquid steel $\mathrm{C}_{\mathrm{p}}=825 \mathrm{~J} / \mathrm{kg} \mathrm{K}$, for solid steel $\mathrm{C}_{\mathrm{p}}$ depends on temper- 
ature, ${ }^{9)}$ and in the mush zone $\mathrm{C}_{\mathrm{p}}$ was evaluated by means of the rule of mixtures), and $\mathrm{L}$ is the latent heat of steel $(\mathrm{L}=272$ $\mathrm{kJ} / \mathrm{kg}$ ).

In the mold, the boundary condition was set by considering the following relation for the local heat flux density: ${ }^{13)}$

$$
q(z)=q_{a} \cdot e^{-\alpha \cdot z}
$$

where $\mathrm{z}$ is the coordinate along the round axis $(\mathrm{z}=0$ at the meniscus), $\alpha$ is a constant (it was set to 1 ), ${ }^{14)}$ and $\mathrm{q}_{\mathrm{a}}$ is the local apparent heat flux density at the meniscus. It can be determined that: ${ }^{15}$

$$
q_{a}=\frac{\alpha \cdot \Delta T_{w}^{T} \cdot \rho_{W} \cdot C_{W} \cdot Q}{P_{m}} \cdot \frac{1}{1-e^{-\alpha \cdot H_{m}}}
$$

where $\rho_{\mathrm{w}}$ and $\mathrm{C}_{\mathrm{w}}$ are the density and the specific heat of water at the average temperature in the mold, $\Delta \mathrm{T}^{\mathrm{T}}{ }_{\mathrm{w}}$ is the total increase in the cooling water temperature, $\mathrm{P}_{\mathrm{m}}$ and $\mathrm{H}_{\mathrm{m}}$ are the perimeter and length of the mold, respectively, and $\mathrm{Q}$ is the volume flow rate of cooling water.

In the secondary cooling region, the boundary conditions are given by the heat exchange due to convection and radiation. The coefficient of convection, $\mathrm{h}_{\mathrm{c}}$, was thus calculated using the following relation: ${ }^{13)}$

$$
h_{c}=392.5 \cdot W_{w}^{0.55} \cdot\left(1-0.0075 \cdot T_{w}\right)
$$

where $\mathrm{W}_{\mathrm{w}}$ is the volumetric water flow rate of secondary cooling and $\mathrm{T}_{\mathrm{w}}$ is the temperature of the cooling-water spray. The coefficient of radiation was calculated using the usual Stefan-Boltzmann equation. The cooling effect exerted by the rollers played a minor role and was neglected here.

Equation (4) was then solved by the finite-difference method using a program made using Java code. The input parameters of the programme are: steel composition, casting temperature and speed, round billet size, volume flow rate of cooling water in the mold, and the cooling conditions of the different zones in the secondary region.

The program was first validated using the analytical model developed by Alizadeh et al. ${ }^{15)}$ and the shell thickness profile reported in Ming et al. ${ }^{12)}$ In addition, the model was validated by measuring the surface temperatures in different locations on the $410 \mathrm{~mm}$ diamater round billet using a pyrometer. Figure $\mathbf{2}$ compares the predicted temperature profile with the measured data points, demonstrating that the agreement between the predicted values and the pyrometer measurements is quite good. This procedure could not be

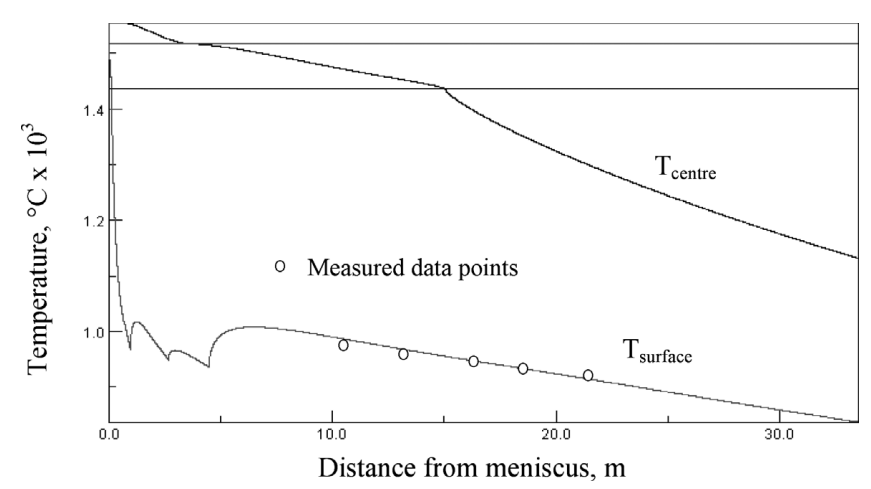

Fig. 2. Comparison between the predicted temperature profile and the measured data points for the $410 \mathrm{~mm}$ diamater round billet.

conducted for the other round billets, but we did measure the surface temperatures at the exit of the mold and after the first secondary cooling zone with satisfactory results. For example, the measured temperatures for the $210 \mathrm{~mm}$ round billet were $1180^{\circ} \mathrm{C}$ and $1090^{\circ} \mathrm{C}$, whereas the predicted values are $1170^{\circ} \mathrm{C}$ and $1085^{\circ} \mathrm{C}$. The model is furthr validated indirectly in the next section, where the model predictions are used to estimate the dendrite arm spacings.

\section{Results and Discussion}

Figures 3(a) and 3(b) presents the results of the metallographic evaluations of $\lambda_{1}$ and $\lambda_{2}$. As expected, and in agreement with the literature data, both $\lambda_{1}$ and $\lambda_{2}$ increase by moving toward the interior of the section, and $\lambda_{2}$ is around one half of $\lambda_{1}{ }^{7)}$ Further, both $\lambda_{1}$ and $\lambda_{2}$ reach plateaus at the center of the samples, almost at the same distance from the surface. Within the plateau, the scatter of the experimental measurements is higher than in the columnar region (the scatter bars are not reported to avoid undue confusion in the graphs), because $\lambda_{1}$ and $\lambda_{2}$ are more difficult to define there. ${ }^{8)}$ As already observed, ${ }^{7,8)}$ this behaviour can be attributed to the transition from columnar to equiaxed growth (CET). This result is in agreement with the experimental measurements of the position of the CET listed in Table 2 (Fig. 4 shows a region with the transition from columnar zone to the equiaxed zone). This table also includes the ratios between the CET and the radius of each round billet.

The results shown in Fig. 3(b) further show that the

(a)

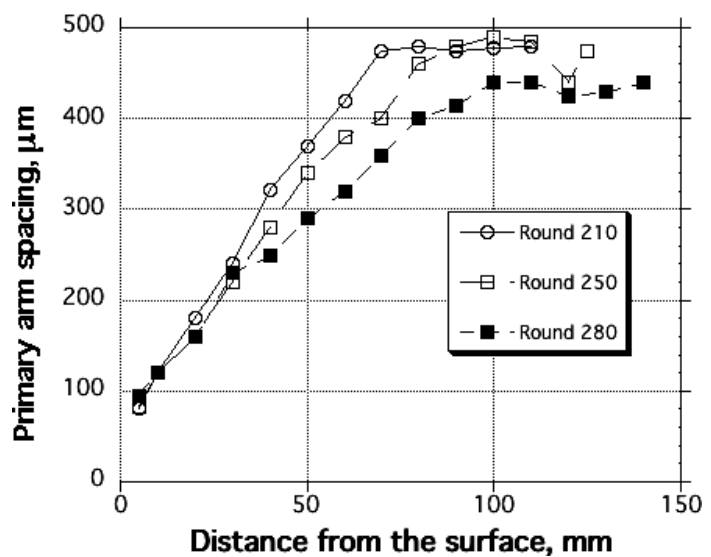

(b)

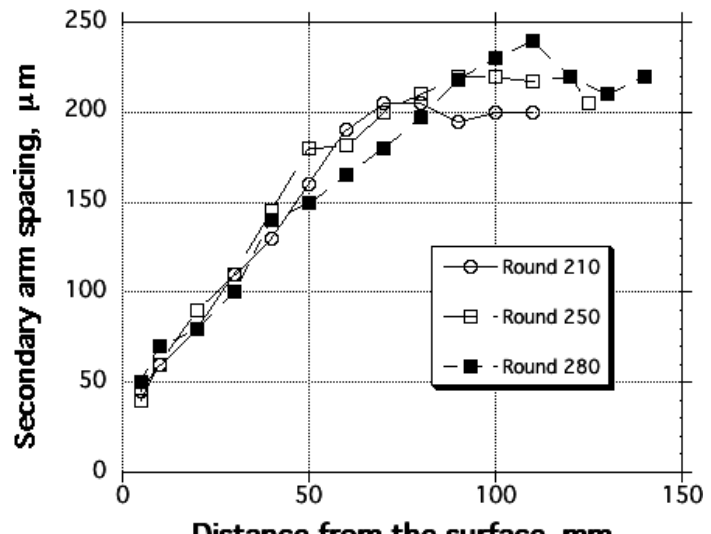

Fig. 3. Average values of primary (a) and secondary (b) arm spacings for the billets under study. 
Table 2. Experimental data for the onset of the plateau of $\lambda_{2}$ and for the CET.

\begin{tabular}{l|c|c|c}
\hline & $\begin{array}{c}\text { Distance from the surface of the } \\
\text { onset of the plateaux of } \lambda_{1}, \mathrm{~mm}\end{array}$ & $\begin{array}{c}\text { CET (experimental } \\
\text { measurements), } \mathrm{mm}\end{array}$ & CET/R (radius) ratio \\
\hline $210 \mathrm{~mm}$ round billet & 70 & 65 & 0.62 \\
\hline $250 \mathrm{~mm}$ round billet & 80 & 77 & 0.61 \\
\hline $280 \mathrm{~mm}$ round billet & 90 & 85 & 0.61 \\
\hline
\end{tabular}

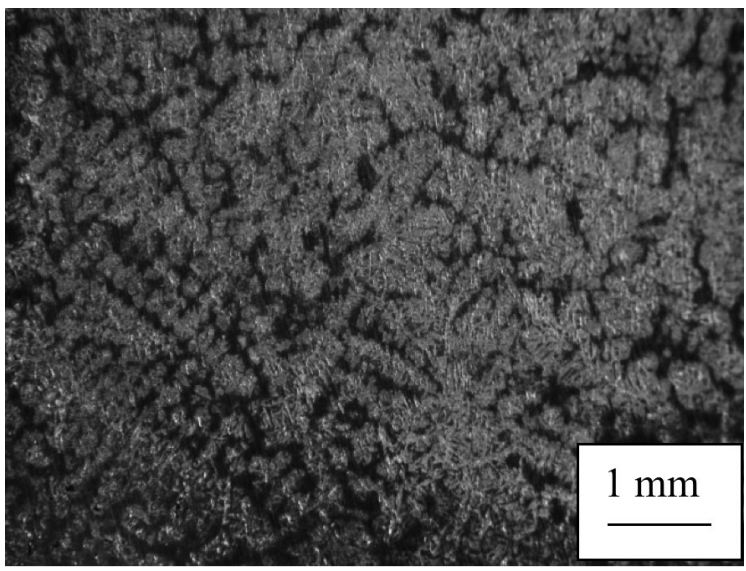

Fig. 4. Region with the transition from the columnar zone to the equiaxed zone, in the $250 \mathrm{~mm}$ round billet.

experimental values for $\lambda_{2}$ in the equiaxed zone are quite large, around $220 \mu \mathrm{m}$. These values are in agreement with those reported by Choudhary and Ganguly ${ }^{5)}$ for CC products obtained without electromagnetic stirring.

The heat transfer model can be used to obtain the parameters $R, G$ and $t_{f}$ as a function of the distance from the surface. To determine $\mathrm{R}$, the solidifying columnar front was set as a fraction of the solid, $f_{s}$, of $0.3 \cdot{ }^{10,11)}$ The following relations were used to $G$ and $t_{f}:{ }^{7 \text { ) }}$

$$
\begin{gathered}
G=\frac{\Delta T}{w} \\
t_{f}=\frac{\Delta T}{R \cdot G}
\end{gathered}
$$

where $\mathrm{w}$ is the length of the mesh ahead of the solidification front and $\Delta \mathrm{T}$ is the thermal gradient along this length. The results of this evaluation are reported in Fig. 5.

According to its definition, $\mathrm{R}$ actually represents the velocity of the isotherm for $\mathrm{f}_{\mathrm{s}}=0.3$, and it only equals the columnar solidifying front velocity before the CET. ${ }^{2)}$ The same reasoning is valid for $\mathrm{G}$, and after the CET, $\mathrm{G}$ represents the thermal gradient at the isotherm for $f_{s}=0.3$. As expected, $\mathrm{R}$ and $\mathrm{G}$ decrease with increasing distance from the surface as long as solidification is columnar. At a certain distance from the surface, $\mathrm{R}$ is found to increase rapidly and $\mathrm{G}$ to decrease rapidly. A similar effect was also observed by Mapelli and Borgiola ${ }^{11)}$ and Long et al. ${ }^{16)}$ A comparison with the data listed in Table 2 shows that this particular behavior is attained in the equiaxed zone. Correspondingly, the solidification time, $t_{f}$, is seen to increase with the distance from the surface and to reach a plateau close to the center of the round billet.

As shown by Eqs. (2) and (3), the calculated values of R, $\mathrm{G}$ and $\mathrm{t}_{\mathrm{f}}$ can be used to evaluate $\lambda_{1}$ and $\lambda_{2}$. For this, the con- (a)

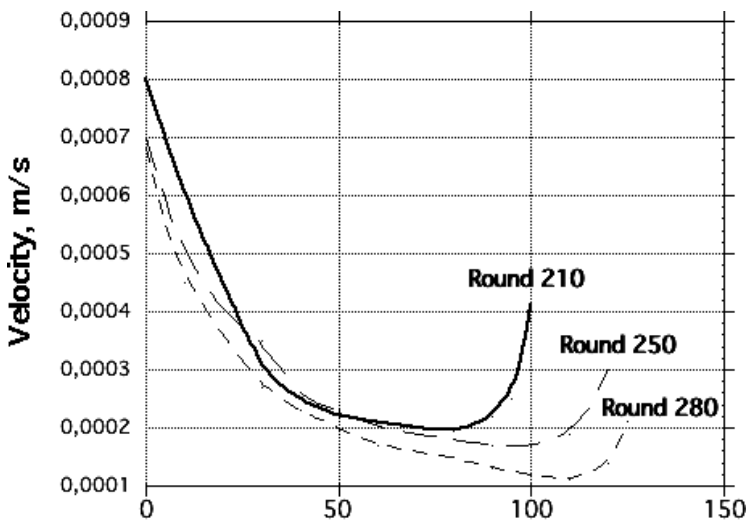

Distance from the surface, $\mathrm{mm}$

(b)

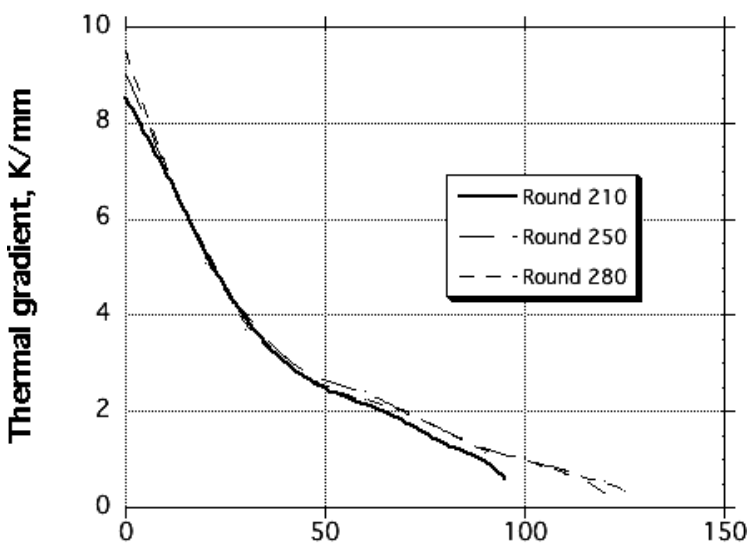

Distance from the surface, $\mathrm{mm}$

(c)

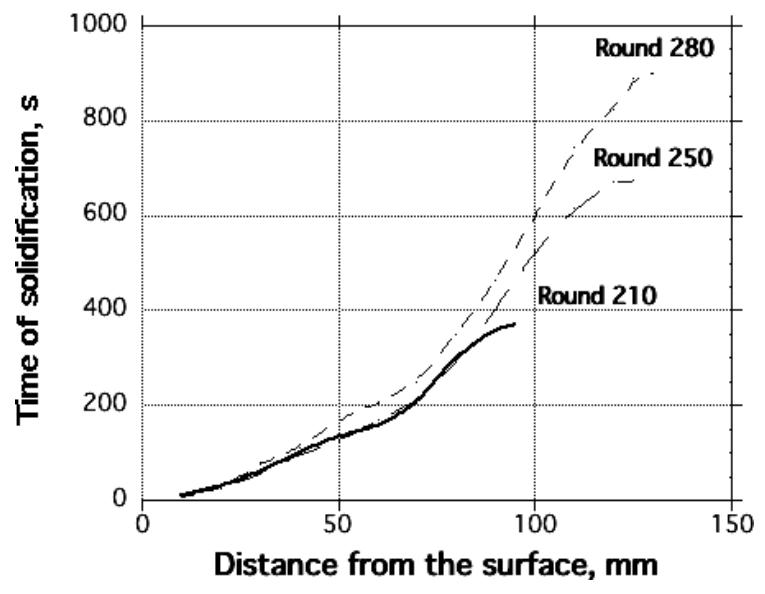

Fig. 5. Calculated solidification parameters: (a) growth velocity of the solidifying front, R; (b) thermal gradient, G; (c) local time of solidification, $\mathrm{t}_{\mathrm{f}}$.

stants $\mathrm{N}$ and $\mathrm{M}$ can be considered as adjustable parameters. As an example, Fig. 6 shows the predicted $\lambda_{1}$-values obtained by setting $\mathrm{N}=70$ (with $\mathrm{R}$ in $\mathrm{m} / \mathrm{s}, \mathrm{G}$ in $\mathrm{K} / \mathrm{mm}$ ) in the case of the $250 \mathrm{~mm}$ diameter round billet. Note that the prediction is very close to the experimental values up to a 
distance of about $40 \mathrm{~mm}$ from the billet surface, i.e., as long as the solidification growth is columnar. In fact, Eq. (2) is not applicable in the equiaxed region since $\lambda_{1}$ is also influenced by the carbon enrichment of the liquid. ${ }^{5)}$ The same results have been obtained from the other CC products, and this is a further confirmation of the validity of the thermal model developed here.

From the point of view of the quality of the $\mathrm{CC}$ products, the control of the position of the CET is of paramount importance, as stated in the Introduction. In the present investigation, the CET/R ratio is around 0.61 (see Table 2), which is considered as an optimal value for the present production process. However, it is important to understand how changing the operational parameters would influence this ratio.

To determine the influence of the parameters, it is necessary to obtain a procedure able to predict the $\mathrm{CET} / \mathrm{R}$ ratio as a function of the operational parameters. This can be done according to the approach proposed by Hunt (Eq. (1)). However, this approach is difficult to employ in practice, as it requires the knowledge of several parameters that are not available or can only be computed after the combined thermal and microstructural analysis. ${ }^{10,11)}$ As shown by Kurz et al., ${ }^{17)}$ however, the nucleation undercooling can be neglected when $\mathrm{R}$ is high (i.e., $\Delta \mathrm{T}_{\mathrm{n}} \approx 0$ ), and the columnar to equiaxed transition occurs when:

$$
\frac{G^{n}}{R} \leq C
$$

where $\mathrm{n}$ and $\mathrm{C}$ depend on the alloy system. ${ }^{17)}$ Therefore, from Figs. 5(a) and 5(b), we obtained the values of $G$ and $\mathrm{R}$ at the CET, and then we fitted the experimental results using Eq. (11). The obtained values are: $n=2.93, C=1.39$
$10^{13}$ (with $\mathrm{R}$ in $\mathrm{m} / \mathrm{s}, \mathrm{G}$ in $\mathrm{K} / \mathrm{m}$ ). Rapid cooling conditions have been reported when $\mathrm{n}$ is between 2 and $3 .{ }^{17)}$ Equation (11) can therefore be conveniently used to evaluate the role of relatively small variations in the operating conditions from the base conditions.

We first consider the role of casting speed in the case of the $250 \mathrm{~mm}$ round billet. Two values of the casting speed were analyzed: 0.9 and $1.1 \mathrm{~m} / \mathrm{min}$. From the thermal analysis, the evolutions of $\mathrm{G}$ and $\mathrm{R}$ were obtained as a function of the distance from the surface, and the dependence of the ratio $G^{2.93} / R$ on this distance was then plotted in Fig. 7. The position of the CET was then obtained by observing where such curves intersect the value of $C=1.3910^{13}$ (with $\mathrm{R}$ in $\mathrm{m} / \mathrm{s}$, $\mathrm{G}$ in $\mathrm{K} / \mathrm{m}$ ). The CET was observed at 72 and $82 \mathrm{~mm}$ from the surface of the billet for the $1.1 \mathrm{~m} / \mathrm{min}$ and $0.9 \mathrm{~m} / \mathrm{min}$ conditions, respectively.

The obtained data show that the CET decreases as the casting speed is increased, in agreement with data reported in Ref. 10. Of course, as the casting speed is increased, the shell thickness at the exit of the mold is decreased and the metallurgical length is increased, both of which may negatively influence the operational conditions and favor the formation of particular defects such as inner cracks. Table 3 lists the calculated values of all these parameters.

The effect of the tundish superheat was also considered for the $250 \mathrm{~mm}$ round billet, using the same approach. Superheats of 30 or $50^{\circ} \mathrm{C}$, i.e., $10^{\circ} \mathrm{C}$ above or below the base value, produced only a weak variation in the CET position, as shown in Fig. 8(a). This results is in agreement with published data, ${ }^{10)}$ and can be explained by considering that a variation in the tundish superheat gives rise to a variation in the evolutions of $\mathrm{G}$ and $\mathrm{R}$ in such a way that the ratio $\mathrm{G}^{2.93} / \mathrm{R}$ is not greatly modified. Finally, we considered the

Table 3. Predicted data for the $250 \mathrm{~mm}$ round billet.

\begin{tabular}{c|c|c|c}
\hline $\begin{array}{c}\text { Casting speed, } \\
\text { m/min. }\end{array}$ & $\begin{array}{c}\text { Position of the CET, } \\
\mathrm{mm}\end{array}$ & $\begin{array}{c}\text { Shell thickness at the } \\
\text { mould exit, mm }\end{array}$ & $\begin{array}{c}\text { Metallurgical length, } \\
\mathrm{m}\end{array}$ \\
\hline 0.9 & 72 & 14.2 & 15 \\
1 & 77 & 16 & 16.9 \\
1.1 & 82 & 18 & 18.9 \\
\hline
\end{tabular}

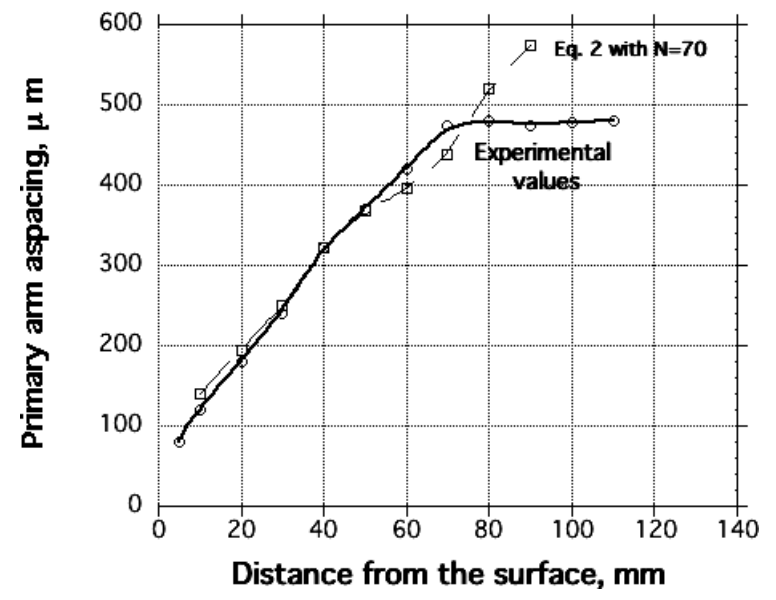

Fig. 6. Experimental and predicted values (by means of Eq. (2)), of the primary arm spacing in the case of the $250 \mathrm{~mm}$ round billet.

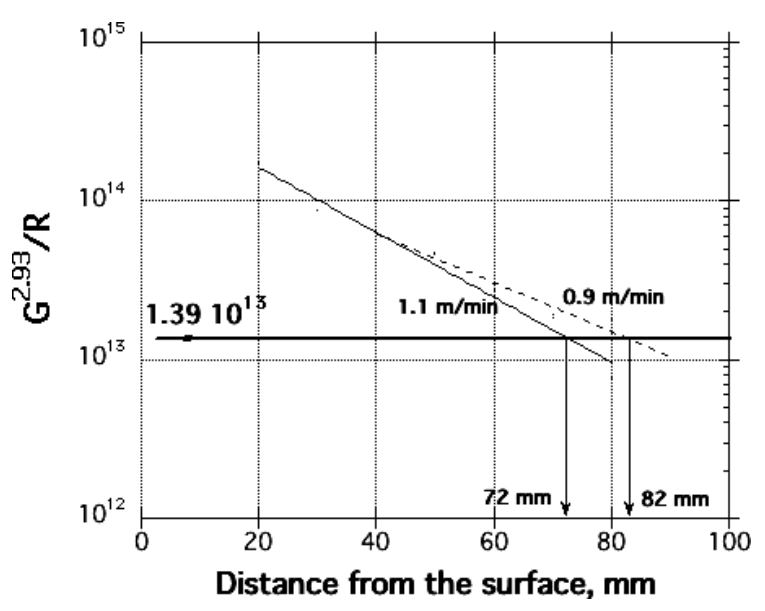

Fig. 7. Estimation of the CET of the $250 \mathrm{~mm}$ round billet using Eq. (11) $(\mathrm{R}$ in $\mathrm{m} / \mathrm{s}, \mathrm{G}$ in $\mathrm{K} / \mathrm{m})$. 
(a)

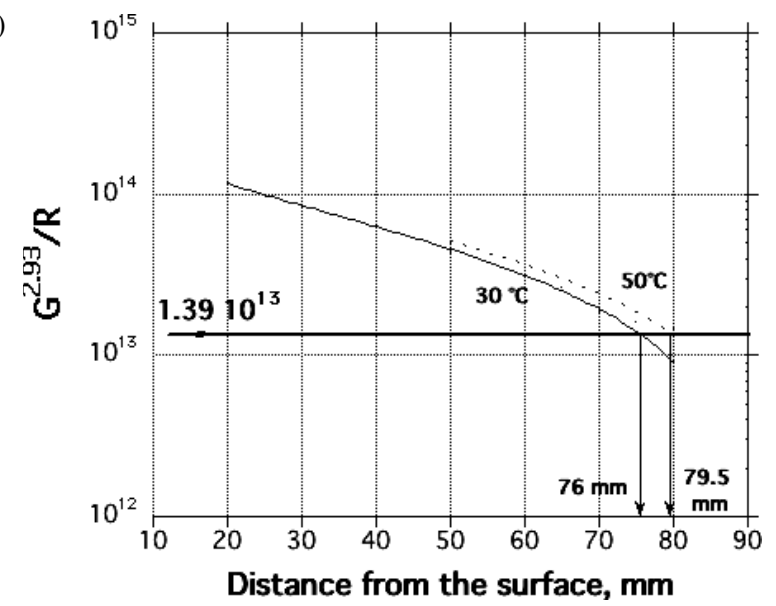

(b)

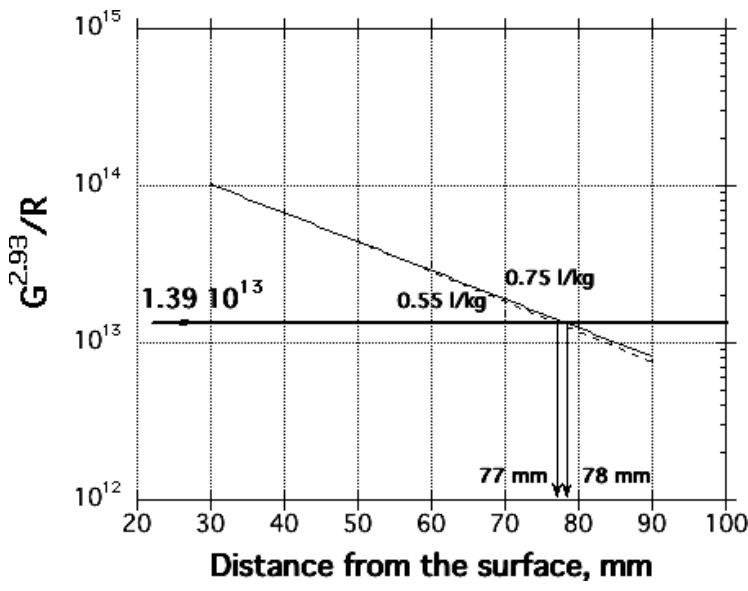

Fig. 8. Estimation of the CET of the $250 \mathrm{~mm}$ round billet using Eq. (11) $(\mathrm{R}$ in $\mathrm{m} / \mathrm{s}, \mathrm{G}$ in $\mathrm{K} / \mathrm{m})$. (a) role of the superheat; (b) role of the secondary water cooling.

effect of an increase in the intensity of the secondary water cooling to $0.75 \mathrm{l} / \mathrm{kg}$ steel (Fig. 8(b)). The position of the CET is predicted to increase to a distance of $78 \mathrm{~mm}$ from the billet surface, in agreement with literature data. ${ }^{10,18)}$

The analysis presented in this investigation yields several important findings regarding the influence of the operational parameters on the internal quality of $\mathrm{CC}$ products. It is quite simple as the parameters $\mathrm{n}$ and $\mathrm{C}$ of Eq. (11) depend on the steel characteristics and may in principle be obtained from only two experimental datasets. Although the validity of the Hunt's model is widely recognized and the simplification performed to obtain Eq. (11) is fully justified by theoretical and experimental arguments, ${ }^{10,17)}$ it is clear that this approach requires further confirmation by experimental investigations specific to each situation.

\section{Conclusions}

(1) The dendritic microstructures of three round billets made from a low carbon steel (containing $0.14 \% \mathrm{C}$ ) and produced by continuous casting were investigated, and the values of the primary and secondary arm spacing were determined.

(2) A numerical heat transfer model was then developed and validated with reference to experimental temperature measurements and also with reference to the microstructural characterization. The model was then used to calculate the local solidification time, the local thermal gradient and the local time for solidification as a function of the distance from the round billet surface.

(3) With reference to the Hunt's model, a simplified relation for the prediction of the columnar to equaxial transition (CET) was then confirmed and used to relate such a transition to the continuous casting operational parameters. For the steel under study, the transition occurs when:

$$
\frac{G^{2.93}}{R} \leq 1.39 \cdot 10^{13}
$$

(with $\mathrm{R}$ in $\mathrm{m} / \mathrm{s}, \mathrm{G}$ in $\mathrm{K} / \mathrm{m}$ ). In agreement with literature data, the CET was then shown to depend on the casting velocity, the tundish superheat and the intensity of secondary cooling.

\section{REFERENCES}

1) W. R. Irvin: Continuous Casting of Steel, The Institute of Materials, London, (1983).

2) M. A. Martorano and V. B. Biscuola: Acta Mater., 57 (2009), 607.

3) J. D. Hunt: Mater. Sci. Eng., 65 (1984), 75.

4) M. C. Flemings and T. Koseki: The Making Shaping and Treating of Steel Casting Volume, The AISE Steel Foundation, Pittsburgh, (2003), Chapter 6, 1

5) S. K. Choudhary and S. Ganguly: ISIJ Int., 47 (2007), 1759.

6) W. Kurtz and D. J. Fisher: Acta Metall., 29 (1981), 11.

7) J. M. Cabrera-Marrero, V. Carreno-Galindo, R. D. Morales and F. Chavez-Alcala: ISIJ Int., 38 (1988), 812.

8) S. Louhenkilpi, J. Miettinen and L. Holappa: ISIJ Int., 46 (2006), 914.

9) Y. Meng and B. G. Thomas: Metall. Mater. Trans., 34B (2003), 685.

10) H. Shibata, S. Itoyama, Y. Kishimoto, S. Takeuchi and H. Sekiguchi: ISIJ Int., 46 (2006), 921.

11) C. Mapelli and S. Baragiola: Ironmaking Steelmaking, 35 (2008), 441.

12) H. Wang, G. Li, Y. Lei, Y. Zhao, Q. Dai and J. Wang: ISIJ Int., 45 (2005), 1291.

13) K. Schwerdtfeger: The Making Shaping and Treating of Steel Casting Volume, The AISE Steel Foundation, Pittsburgh, (2003), Chapter 4, 29.

14) M. Alizadeh, A. J. Jahromi and O. Abouali: Comput. Mater. Sci., 44 (2008) 807.

15) M. Alizadeh, A. J. Jahromi and O. Abouali: ISIJ Int., 48 (2008), 161.

16) M. Long, L. Zhang and F. Lu: ISIJ Int., 50 (2010), 1792.

17) W. Kurz, C. Bezencon and M. Gaumann: Sci. Technol. Adv. Mater., 2 (2001), 185

18) M. Okimori, M. Tsuchida and K. Inaoka: Tetsu-to-Hagané, 80 (1994), T25 